Boise State University

ScholarWorks

Counselor Education Faculty Publications and

Presentations

Department of Counselor Education

$7-1-2010$

Reducing Heavy Drinking Among First Year Intercollegiate Athletes: A Randomized Controlled Trial of Web-Based Normative Feedback

Diana M. Doumas

Boise State University

Tonya Haustveit

Boise State University

Kenneth M. Coll

Boise State University 


\title{
Reducing Heavy Drinking Among First Year Intercollegiate Athletes: A Randomized Controlled Trial of Web-Based Normative Feedback
}

\author{
Diana M. Doumas, Tonya Haustveit, and Kenneth M. Coll \\ Boise State University
}

\begin{abstract}
Author Note
Correspondence concerning this article should be addressed to Diana M. Doumas, Department of Counselor Education, Boise State University, 1910 University Drive, Boise, ID 83725-1715, USA. Phone: (208) 426-2646. Fax: (208) 426-2046. E-mail: dianadoumas@ @oisestate.edu.

The authors would like to thank Elizabeth Hannah for her assistance in program evaluation, and Lisa Parker, Christina Van Tol, Val Cleary, and Chelsea Herman for their assistance in program development and participant recruitment.

The contents of this report were developed under a grant from the U.S. Department of Education (Q184H070011). However, those contents do not necessarily represent the policy of the U.S. Department of Education, and you should not assume endorsement by the federal government.
\end{abstract}

\begin{abstract}
This study evaluated the efficacy of a web-based personalized normative feedback program targeting heavy drinking in first year intercollegiate athletes. The program was offered through the Athletic Department first year seminar at a NCAA Division I university. Athletes were randomly assigned to either a web-based feedback group or a comparison condition. Results indicated high-risk athletes receiving the intervention reported significantly greater reductions in heavy drinking than those in the comparison group. Additionally, intervention effects were mediated by changes in perceptions of peer drinking. Findings support the use of web-based normative feedback for reducing heavy drinking in first year intercollegiate athletes.
\end{abstract}

Key Words: alcohol; drinking, intercollegiate athletes; normative feedback; online

Heavy drinking represents a significant problem on college campuses in the United States, with over $30 \%$ of students meeting criteria for a diagnosis of alcohol abuse (Knight, et al., 2002). National survey data indicate 80$85 \%$ of U.S. college students report drinking (O'Malley \& Johnston, 2002) and 40-45\% report a heavy drinking episode at least once in the two weeks prior to the survey (Wechsler et al., 2002). Heavy drinking is also associated with multiple social and interpersonal problems such as arguing with friends, engaging in unplanned sexual activity, drinking and driving, getting into trouble with the law, and academic difficulties (Abbey, 2002; Cooper, 2002; Hingson, Heeren, Zakocs, Kopstein, \& Wechsler, 2002; Perkins, 2002; Vik, Carrello, Tate, \& Field, 2000; Wechsler , Lee, Kuo, \& Lee, 2000). Additionally, heavy episodic drinking is associated with severe consequences such as unintended injuries, assault, and death (Hingson, Heeren,Winter, \& Wechsler, 2005).

Relative to the general college population, student athletes have been identified as a high-risk group for heavy drinking (Martens, Dams-O'Connor, \& Beck, 2006; Turrisi, Mallett, Mastroleo, \& Larimer, 2006). Research indicates students participating in athletic activity, including varsity, intramural, and club sports, typically drink more heavily and frequently than non-athletes (Doumas, Turrisi, Coll, \& Haralson, 2007; Hildebrand, Johnson, \& Bogle, 2001; Leichliter, Meilman, Presley, \& Cashin, 1998; Nelson \& Wechsler, 2001) and level of athletic involvement is positively related to levels of heavy drinking (Hildebrand et al., 2001; Leichliter et al., 1998). Drinking is particularly problematic for student athletes as alcohol use may result in physical and cognitive performance deficits related to athletic performance demands (Grossbard, Hummer, LaBrie, Pederson, \& Neighbors, 2009). Alcohol use may also lead to emotional problems, such as depression, which may impair athletic performance. Additionally, alcohol use is associated with academic and social problems which may result in poor athletic performance, or in some cases, suspension or removal from the team. Thus, providing effective alcohol intervention programs is an important part of enhancing academic, emotional, and physical performance and among intercollegiate athletes and ensuring team eligibility. 
Several explanations for the high rates of drinking found in the student athlete population have been proposed (see Martens, Dams-O'Connor, \& Beck, 2006). Of these, peer influence has gained attention in the literature as an important social variable that may be related to the elevated levels of drinking among both the general college student population and among student athletes. According to social norming theory (Perkins, 2002), college students overestimate the drinking of their peers and this overestimation is related to heavy drinking as students try to match their drinking to that of their peers. Research indicates overestimation of perceived drinking norms is one of the best predictors of alcohol use among college students (Neighbors, Lee, Lewis, Fossos, \& Larimer, 2007). Further, perceived norms for more proximal groups, such as close friends, are more predictive of drinking behavior than perceived norms for more distal groups, such as typical university students (see Borsari \& Carey 2003; Lewis \& Neighbors, 2006). Similarly, student athletes also believe their peers, including both typical teammates and typical students on campus, drink more than they do (Dams-O'Connor, Martin, \& Martens, 2007; Doumas \& Haustveit, 2008; Thombs, 2000). Consistent with the general college student literature, research indicates perceived peer alcohol use is also the best predictor of alcohol use among athletes (Hummer, LaBrie, \& Lac, 2009). In addition, among student athletes, the typical athlete drinking norm is the strongest predictor of personal alcohol use compared to other peer norms (Dams-O'Connor et al., 2007). Research also suggests that the relationship between personal use and perceived athlete norms is most pronounced in athletes who feel connected to their athletic team (Grossbard et al., 2009).

A large body of research indicates brief interventions providing accurate feedback about peer drinking relative to personal drinking are associated with reductions in alcohol consumption in the general college student population (see Carey, Scott-Sheldon, Carey, \& DeMartini, 2007; Larimer \& Cronce, 2002; 2007). Research also indicates innovative approaches to providing personalized normative feedback, including mailed feedback and webbased feedback, are effective (see Larimer \& Cronce, 2007) and young drinkers may respond better to electronic feedback than to in-person feedback (Kypri, Saunders, \& Gallagher, 2003; Saunders, Kypri, Walters, Laforge, \& Larimer, 2004). Several recent reviews of the literature, however, indicate that there is a need for outcome research examining interventions aimed at reducing heavy drinking for student athletes (Larimer \& Cronce, 2007; Martens, Dams-O'Connor, \& Beck, 2006; Turrisi et al., 2006). Further, as the transition to the first year may be particularly difficult for student athletes (Giacobbi et al., 2004), an important area for college program development is providing effective drinking prevention programming for student athletes during their first year of college. In their review, Martens, Dams-O'Connor and Beck (2006) also emphasize the importance of determining if intervention programs that are effective for college students may also be effective for collegiate athletes.

Although intercollegiate athletes have been identified as a high-risk population for heavy drinking and research indicates providing personalized normative feedback is effective in reducing college student drinking, to date only one study has evaluated the impact of personalized normative feedback on drinking outcomes in a sample of intercollegiate athletes (Doumas \& Haustveit, 2008). Although social norms campaigns have been evaluated (Perkins \& Craig, 2006; Thombs \& Hamilton, 2002), these are implemented as environmental strategies which provide normative data but do not provide individualized personalized feedback relative to the normative data. In contrast, Doumas and Haustveit (2008) evaluated the efficacy of a brief web-based personalized normative feedback program aimed at reducing drinking in a sample of first year intercollegiate athletes. The program was offered through the Athletic Department fall first year seminar. Results indicated for athletes classified as high-risk drinkers, those receiving web-based personalized normative feedback reported significantly greater changes in beliefs about peer drinking and reductions in alcohol use than those receiving web-based education. Additionally, changes in estimates of peer drinking were related to reductions in alcohol use for athletes receiving personalized normative feedback but not for athletes receiving alcohol education.

Although Doumas and Haustveit (2008) provide evidence for the efficacy of web-based personalized normative feedback in reducing drinking in a sample of first year student athletes, two significant methodological issues weaken the generalizability of the study. First, seminar sections were randomly assigned to the two intervention conditions rather than randomly assigning individual athletes to study conditions. Additionally, the initial small sample size was small $(N=52)$ and only $64 \%(n=33)$ of those completed both follow-up assessments. The current study extends the literature by evaluating program efficacy using a larger sample than previous research. Additionally, student athletes, rather than seminar sections, were randomly assigned to either the intervention group or to a comparison condition, resulting in a true randomized controlled design. As the majority of research examining web-based programs has demonstrated efficacy in students identified as high-risk or heavy drinkers (Bersamin, Paschall, Fearnow-Kenney, \& Wyrick, 2007; Chiauzzi, Green, Lord, Thum, \& Goldstein, 2005; Doumas \& Anderson, 2009; Doumas \& Haustveit, 2008; Doumas, Kane, Navarro, \& Roman, in press; Kypri et al., 2004; Neighbors, Larimer, \& Lewis, 2004; Walters, Vader, \& Harris, 2007), we also classified student athletes as high-risk or low-risk drinkers using reports of binge drinking at the baseline assessment. 
The following hypotheses were examined. First, we hypothesized that high-risk athletes in the intervention group would report greater reductions in heavy drinking relative to those in the comparison group. Second, we hypothesized student athletes would estimate typical collegiate athlete and typical college student drinking to be higher than their own drinking. We also predicted that high-risk athletes in the intervention group would reduce their estimates of peer drinking more than those in the comparison group. Third, we were interested in the relationship between changes in perceptions of peer drinking and changes in personal drinking. We hypothesized changes in perceptions of peer drinking would mediate the effect of the intervention on changes in drinking for highrisk athletes.

\section{Participants}

\section{Method}

Intercollegiate athletes were recruited from the Athletic Department at a National Collegiate Athletic Association (NCAA) Division I university in the northwest over a two year period. The program was offered as part of the first year seminar curriculum provided by the Athletic Department. The freshman seminar is designed to assist student athletes with acclimation to the university campus. The course addressed the following areas: academic excellence, athletic leadership, personal development, career development, and involvement in the community. This program was offered during the personal development module.

All first year intercollegiate athletes enrolled in the seminar $(N=113)$ were given an opportunity to participate in the study. Participants were not offered compensation. All participants were informed of the nature of the study, risks and benefits of participation, and information regarding the voluntary nature of participation. All participants were treated according to established American Psychological Association (APA) ethical standards and the research was approved by the University Institutional Review Board.

Student athletes $(N=113)$ were randomly assigned to either the intervention group or comparison group. Because students participated in the intervention program during class time, we needed to provide an alternative activity for the students not completing the intervention. We selected a web-based education program for the comparison program so that students would receive general information about alcohol without receiving personalized normative feedback. In doing so, we also provided a more rigorous control comparison than an assessment-only condition.

Of the 113 eligible student athletes, $62(55 \%)$ were assigned to the intervention condition and $51(45 \%)$ were assigned to the comparison condition. Ages of the participants ranged from $18-20(M=18.08, S D=0.48)$ and $57 \%$ were female. The majority of athletes were Caucasian (70\%), with $16 \%$ African-American, $7 \%$ other, $2 \%$ Asian-American, and 5\% Hispanic. For sport played, 28\% reported football $(n=32), 18 \%$ track $(n=20), 14 \%$ swimming/diving $(n=16), 10 \%$ gymnastics $(n=11), 9 \%$ soccer $(n=10), 6 \%$ tennis $(n=7), 4 \%$ basketball $(n=5)$, $3.5 \%$ golf $(n=4), 3.5 \%$ softball $(n=4), 2 \%$ wrestling $(n=2)$, and $2 \%$ volleyball $(n=2)$. A series of independent sample t-tests and chi square analyses confirmed there were no differences in age, $t(111)=0.76, p=.45$, gender, $\chi^{2}$ $=0.17, p=.68$, ethnicity, $\chi^{2}=4.15, p=.39$, or sport played, $\chi^{2}=4.71, p=.91$, across the two intervention groups. Measures

Alcohol consumption. Recommendations by the National Institute on Alcohol Abuse and Alcoholism (NIAAA) Task Force include assessing patterns of alcohol consumption and including at least three measures of consumption covering quantity, frequency, and heavy use (NIAAA, 2003). We included three measures of alcohol use typically used in studies of college drinking: drinking quantity, frequency of drinking to intoxication, and peak consumption. A drink was defined as "a 12-ounce can or bottle of beer, a 4-ounce glass of wine, or a shot of distilled spirits in a mixed drink". Typical weekly drinking was assessed using a modified version of the Daily Drinking Questionnaire (DDQ, Collins, Parks, \& Marlatt, 1985) in which participants were asked, "Given that it is a typical week, please write the number of drinks you probably would have each day." A response scale is provided for each day of the week (e.g., Monday_, Tuesday_, etc.). Weekly drinking was calculated by combining the reports for the seven days of the week. Frequency of drinking to intoxication was assessed by an item asking the participants to indicate the number of times they have "gotten drunk, or very high from alcohol?". Peak drinking quantity was assessed by an item asking the participants to indicate the number of drinks consumed on the occasion on which they drank the most in the previous month.

Classification of High-Risk vs. Low-Risk Drinkers. We also asked participants to report on the frequency of binge drinking. Following the Harvard School of Public Health College Alcohol Study (CAS), binge drinking was defined as having 5 or more drinks in a row for males (4 or more for females) (Wechsler, Davenport, Dowdall, Moeykens, \& Castillo, , 1994). This item was used as an indicator of high-risk drinking and was used to create a risk variable, with participants indicating one or more occasions of binge drinking in the 3 months at the baseline assessment classified as high-risk drinkers. The 5/4 binge drinking measure has been widely used and supported as an appropriate threshold to identify high-risk drinkers (Wechsler \& Nelson, 2001; 2006) and identified as a 
dangerous level of drinking (NIAAA, 2004). Using this measure, $31 \%$ of the participants were classified as highrisk drinkers (29\% in the intervention group; $33 \%$ of the comparison group) and $69 \%$ were classified as low-risk drinkers.

Perceptions of Peer Drinking. Beliefs about peer weekly drinking quantity for typical collegiate athletes and typical college students were assessed using a modified version of the Daily Drinking Questionnaire (DDQ, Collins et al.,1985). Rather than being asked about their own drinking, participants were given two items in which they were asked to estimate the number of drinks they believe a typical collegiate athlete and a typical college student would drink, "Given that it is a typical week, please write the number of drinks you believe a typical college student (typical collegiate athlete) probably would have each day." A response scale is provided for each day of the week (e.g., Monday__, Tuesday___, etc.). Weekly estimates of typical collegiate athlete drinking and typical college student drinking were each calculated by combining the reports for the seven days of the week. Web-Based Programs

Intervention Program. e-CHUG (http://www.e-chug.com) is a brief web-based program designed to reduce high-risk drinking by providing personalized feedback and normative data regarding drinking and the risks associated with drinking. The program is commercially available and is managed by the San Diego State University Research Foundation. The program is customized for the participating university, including providing normative data for the university population, referrals for the local community, and designing the website using university colors and logos. The personalized normative feedback program takes approximately 30 minutes to complete. The online assessment collects basic demographic information and information on alcohol consumption, drinking behavior, and alcohol-related consequences. Individualized graphed feedback is provided immediately in the following domains: Summary of quantity and frequency of drinking including graphical feedback such as the number of cheeseburgers that are equivalent to alcohol calories consumed, graphical comparison of one's own drinking to U.S. adult and college drinking norms, estimated risk-status for negative consequences associated with drinking and risk-status for problematic drinking based on the participant's Alcohol Use Disorders Identification Test (AUDIT) score, genetic risk, tolerance, approximate financial cost of drinking in the past year, normative feedback comparing one's perception of peer drinking to actual university drinking normative data, and referral information for local agencies.

Comparison Program. The education website consists of facts about alcohol and alcohol consumption and guidelines about how to deal with someone who has had too much alcohol to drink. The website is available at http://www.radford.edu/ kcastleb/toc.html and is free to the public. Participants were asked to "surf" the website for 30 minutes.

\section{Procedure}

All participants were given drinking questionnaires at baseline (the first week in September) and at 3 months (first week in December). All questionnaires at baseline and follow-up assessments were completed in penand-paper format. During the baseline data collection, students were assigned a personal code that was used to identify pre-intervention and follow-up responses from each student, as well as to calculate response rates from baseline to follow-up assessments. After completing questionnaires at baseline, participants in the intervention group completed the 30-minute online intervention and participants in the comparison group "surfed" the educational website for 30 minutes. After completing the questionnaires at the 3-month follow-up, participants in the comparison group completed the 30-minute online intervention and participants in the intervention group "surfed" the educational website for 30 minutes.

\section{Results}

Prior to conducting the study analyses, data were examined for extreme cases that might impact the results. Extreme cases were defined as those that were more than 3.3 standard deviations from the mean on any of the selfreported drinking measures at baseline. This resulted in the identification of seven study participants who were eliminated from the analyses. Overall, 98\% $(n=111)$ of the 113 participants participated in the 3 month web-based intervention and assessment. The two students who did not participate were no longer enrolled in the first year seminar. For the final sample, 56\% $(n=59)$ were in the intervention group $(n=41$ low-risk; $n=18$ high-risk $)$ and $44 \%(n=47)$ were in the comparison group ( $n=34$ low-risk; $n=13$ high-risk).

Changes in Reported Alcohol Consumption

The primary hypothesis of this study was that high-risk student athletes in the intervention group would report significantly greater reductions in drinking relative to those in the comparison group across the fall semester. To test this hypothesis, we conducted three repeated measures analyses of variance (ANOVA) with two factors: Study Group (Intervention; Comparison) and Drinking Risk-Status (High; Low). The three dependent variables were weekly drinking quantity, frequency of drinking to intoxication, and peak drinking quantity. Means and standard deviations for each of the dependent variables at baseline and 3 month assessments are shown in Table 1. 
The pattern of how the drinking variables changed over time by treatment group and risk status is shown in Figure 1. Results indicated the Time $\mathrm{x}$ Group $\mathrm{x}$ Risk-Status was significant for weekly drinking, $F(1,100)=4.26, p$ $<.04$, partial $e^{2} a^{2}=.04$, drinking to intoxication, $F(1,100)=7.23, p<.01$, partial $e^{2} a^{2}=.07$, and peak drinking, $F(1$, $100)=4.08, p<.05$, partial $e t a^{2}=.04$. As predicted, high-risk student athletes in the intervention group reported they had reduced their drinking significantly more than those in the comparison group, while reported changes in drinking between the intervention and comparison groups were similar for low-risk student athletes (see Figure 1). Examination of the means in Table 1 indicates that high-risk student athletes in the intervention group reduced their weekly drinking quantity by $46 \%$ compared to a $21 \%$ increase in drinks in the comparison group. Similarly, highrisk student athletes in the intervention group reduced their frequency of drinking to intoxication by $46 \%$ compared to an increase of $6 \%$ in the comparison group. Finally, high-risk student athletes in the intervention group reduced their peak drinking quantity by $32 \%$ compared to an increase of $11 \%$ in the comparison group.

Perception of Peer Drinking

Baseline reports for self, typical collegiate athletes, and typical college student drinking indicated first year student athletes reported drinking fewer drinks per week $(M=3.25, S D=4.8)$ than they believed a typical collegiate athlete drinks $(M=8.88, S D=6.5)$ and a typical college student drinks $(M=19.19, S D=12.5)$. A series of twotailed paired t-tests indicated significant differences between self report and report of a typical collegiate athlete, $t(105)=-8.43, p<.001, d=-.99$, self report and report of a typical college student, $t(105)=-13.78, p<.001, d=-$ 1.68 , and report of a typical collegiate athlete and a typical college student, $t(105)=-11.73, p<.001, d=-1.03$. As predicted, results suggest that first year athletes reported higher levels of weekly drinking for both collegiate athletes and college students than they reported for themselves.

Changes in Perceptions of Peer Drinking

To examine differences in beliefs about peer drinking from baseline to 3 month reports, we conducted two repeated measures analyses of variance (ANOVA) with two factors: Study Group (Intervention; Comparison) and Drinking Risk-Status (High; Low). The dependent variables in the two analyses were beliefs about drinking for a typical collegiate athlete and beliefs about drinking for a typical college student. Means and standard deviations for beliefs about peer weekly drinking at baseline and 3 month assessments by study condition and risk-status are shown in Table 2.

Results of the repeated-measures ANOVA for beliefs about a typical collegiate athlete weekly drinking indicated a significant interaction effect for Time x Group x Risk-Status, $F(1,100)=4.08, \mathrm{p}<.05$, partial $e t a^{2}=.04$. For typical college student weekly drinking, there was a trend toward significance for the Time $\mathrm{x}$ Group $\mathrm{x}$ RiskStatus interaction effect, $F(1,100)=3.44, \mathrm{p}<.07$, partial $e t a^{2}=.03$. As predicted, high-risk student athletes in the intervention group reported they had reduced their perceptions of peer drinking significantly more than those in the comparison group, while reported changes in perceptions of peer drinking between the intervention and comparison groups were similar for low-risk student athletes (see Figure 2). Examination of the means in Table 2 indicates that high-risk student athletes in the intervention group reduced their perceptions of typical collegiate athlete drinking by $15 \%$ compared to a $96 \%$ increase in drinks in the comparison group. Similarly, high-risk student athletes in the intervention group reduced their perceptions of typical college student drinking by $20 \%$ compared to a $45 \%$ increase in drinks in the comparison group.

Changes in Perceptions of Peer Drinking and Changes in Alcohol Consumption

We next conducted a series of hierarchical regression analyses to examine whether the effect of the intervention on drinking could be explained by the change in estimates of peer drinking. Following Baron $\&$ Kenny (1986), separate regression analyses were conducted to determine whether the intervention was significantly associated with changes in estimates of peer drinking, whether changes in estimates of peer drinking predicted changes in drinking, and whether the effect of the intervention on drinking was accounted for by changes in peer drinking estimates. Change scores from baseline to the 3 month follow-up were calculated for both estimates of peer drinking and weekly drinking. We also used the Group x Risk-Status interaction in the following analyses to account for the group differences by risk status.

As hypothesized, results of a series of regression analyses indicated changes in estimates of peer drinking mediated the relationship between the effect of the intervention and changes in drinking. Specifically, the Group $x$ Risk-Status interaction predicted changes in estimates of peer drinking $(\beta=.67, p<.05)$ and estimates of peer drinking predicted changes in drinking $(\beta=.25, p<.01)$. In the final regression, the Group $\mathrm{x}$ Risk-Status interaction predicted changes in drinking and the effect of the intervention on changes in drinking was no longer significant after controlling for the effect of changes in estimates of peer drinking (see Table 3 ). 


\section{Discussion}

Student athletes have been identified as a high-risk group for heavy drinking on college campus. Because alcohol use is associated with multiple problems that may impact athletic performance and eligibility, it is important to provide effective alcohol intervention programs for intercollegiate athletes. The aim of this study was to evaluate the efficacy of a web-based personalized normative feedback program in reducing heavy drinking among first year intercollegiate athletes. Although a growing body of literature indicates web-based personalized normative feedback is effective for reducing high-risk drinking in college students (see Larimer \& Cronce, 2007; Walters, Miller, \& Chiauzzi, 2005; Walters \& Neighbors, 2005), we could find only one study that has examined the efficacy of a web-based personalized normative feedback to reduce heavy drinking specifically among intercollegiate athletes (Doumas \& Haustveit, 2008). Thus, this study adds to the literature by providing further evidence to support the efficacy of web-based personalized normative feedback and identifies an intervention strategy that effectively reduced heavy drinking for high-risk students in this sample of first year athletes.

Results of this study confirmed the hypothesis that the reductions in drinking in the intervention group would be significantly greater than reductions in the comparison group for high-risk student athletes. High-risk student athletes in the intervention group reported greater reductions in weekly drinking, frequency of drinking to intoxication, and peak alcohol consumption than those in the comparison condition, whereas changes in drinking for low-risk student athletes were similar across the two study conditions. High-risk student athletes in the intervention group reported a $46 \%$ reduction in weekly drinking quantity, $46 \%$ reduction in frequency of drinking to intoxication, and $32 \%$ reduction in peak drinking levels compared to increases of $21 \%, 6 \%$, and $11 \%$ for each drinking variable, respectively, in the comparison group. These findings are consistent with research indicating that web-based personalized normative feedback programs are effective in reducing heavy drinking in college students in general (see Larimer \& Cronce, 2002; 2007), and first year intercollegiate athletes in particular (Doumas \& Haustveit, 2008). In addition, the finding that web-based feedback was effective for first year student athletes classified as high-risk drinkers parallels research on web-based programs for both college students (Bersamin et al., 2007; Chiauzzi et al., 2005; Doumas \& Anderson, 2009; Doumas et al., in press; Kypri et al., 2004; Neighbors et al., 2004; Walters et al., 2007) and first year intercollegiate athletes (Doumas \& Haustveit, 2008).

Results also indicated first year athletes reported both typical collegiate athletes and typical college students drink more than they do. The direction and magnitude of the means were consistent with research indicating athletes believe their teammates drink more than they do and that typical college students drink more than their teammates (Dams-O'Connor et al., 2007; Doumas \& Haustveit, 2008; Thombs, 2000). Findings also supported the hypothesis that high-risk student athletes receiving personalized normative feedback about peer drinking would adjust their beliefs about peer drinking downward. For high-risk athletes, changes in beliefs about typical collegiate athlete drinking and typical student drinking were reduced in the intervention group relative to the comparison group. High-risk student athletes in the intervention group reduced their perceptions of typical collegiate athlete drinking by $15 \%$ and typical college students drinking by $20 \%$ compared to a $96 \%$ and $45 \%$ increase, respectively, in the comparison group. Thus, although the intervention provided normative feedback about university-specific college student drinking, normative perceptions about both collegiate athlete and college student drinking quantity were reduced.

We also examined the relationship between changes in drinking and changes in the perceptions of peer drinking. As predicted, results indicated changes in estimates of typical collegiate athlete drinking from baseline to the 3 month follow-up mediated the effect of the intervention on changes in drinking quantity. That is, the effects of the intervention were accounted for by the changes in estimates of peer drinking. These results are consistent with previous research using change score correlations to demonstrate that changes in social norms were related to changes in drinking (Doumas \& Haustveit, 2008; Martens et al., 2007) and research on web-based feedback programs that indicate reductions in drinking are mediated by reductions in estimates of peer drinking (Doumas, McKinley, \& Book, 2009; Neighbors et al., 2004; Walters et al., 2007). Because perceptions of peer drinking and reports of personal drinking were collected at the same time points, we are not able to conclude that changes in perceptions of peer drinking caused the changes in personal drinking. The personalized normative feedback intervention, however, did result in a decrease in perception of peer drinking estimates which in turn was associated with decreases in personal alcohol consumption. Thus, findings provide supportive evidence that the intervention led to a reduction in estimates of peer drinking norms which, in turn, led to a reduction in personal drinking quantity. Study Limitations and Future Directions

Although this study adds to the literature by providing evidence for the efficacy of a web-based personalized normative feedback program for decreasing drinking in high-risk student athletes, several limitations deserve note. First, information in this study was obtained through self-report. Although self-report potentially leads 
to biased or distorted reporting, college students may not be motivated to misrepresent their alcohol use as heavy drinking is perceived as normal in the college setting (Borsari \& Muellerleile, 2009). Self-reported alcohol use is, however, common practice in studies evaluating online interventions for college and university students. Further, results of a recent meta-analysis support this usage, indicating that the reliability of self-reported drinking in college students is good, with little bias reported between participant and collateral reports (Borsari \& Muellerleile, 2009). Second, although results indicated the changes in drinking between the intervention and comparison group were statistically significant, the effect sizes were in the small to medium range, suggesting that the practical significance of these findings may be questionable. The practical significance, however, is supported by a $32 \%$ - $46 \%$ reduction in drinking variables for the intervention group compared to increases of $6 \%-21 \%$ in drinking variables for the comparison group. Next, although university-specific norms were used as the personalized normative feedback in this study, research suggests that athlete drinking is influenced more by athlete norms than typical student norms (Dams-O'Connor et al., 2007). Therefore, future research should examine whether or not changes in drinking are greater if the normative feedback presented provides information about athlete drinking norms rather than typical student drinking norms. Finally, research indicates there are differences in athlete drinking patterns during the inseason and off-season, (Martens, Dams-O'Connor, \& Duffy-Paiement, 2006; NCAA, 2001; Thombs, 2000) and across sports (Martens, Watson, \& Beck, 2006; NCAA, 2001). Future studies with larger samples should examine whether or not there are differences in effectiveness of web-based normative feedback programs both in-season and off-season and for athletes participating in different sports.

Implications for Practitioners of Sport Psychology

Results of this study have important implications for intervention efforts aimed at reducing drinking for first year intercollegiate athletes. First, $31 \%$ of this sample was classified as high-risk drinkers, indicating nearly one third of the student athletes in this sample reported binge drinking at least once in the past 2 weeks prior to the baseline survey. Additionally, first year athletes in the comparison group actually increased their drinking over the course of the fall term. Thus, athletic staff and other university personnel need to be careful not to minimize drinking as "typical college drinking", but to recognize that drinking may become heavier as the academic year progresses.

The brief intervention used in this study may be used as a general intervention program for intercollegiate athletes as described in this study. Web-based normative feedback programs such as e-CHUG may also be used with athletes outside of the university setting. Sport psychologists may use web-based personalized feedback programs such as e-CHUG with their individual clients. Although athletes may be hesitant to report alcohol-related issues to coaches, advisors, or their psychologist, they may be more willing to complete an online program in between counseling sessions. Athletes may then bring their feedback into the counseling session to discuss with their psychologist who may then use motivational interviewing strategies to help athletes make better choices about drinking.

In conclusion, although student athletes remain a high-risk population for drinking, very few controlled studies have evaluated the impact of individual-level intervention programs targeting collegiate athlete drinking (see Larimer \& Cronce, 2007; Martens, Dams-O'Connor, \& Beck, 2006; Turissi et al., 2006). Additionally, although research has demonstrated that personalized normative feedback programs are effective in decreasing alcohol use in the college student population (see Carey et al., 2007; Larimer \& Cronce, 2007), this is only the second study to examine the efficacy of a web-based personalized normative feedback program for intercollegiate athletes. Results of this study suggest providing a web-based personalized normative feedback program during the fall semester of the first year is effective for reducing heavy drinking in first year intercollegiate athletes. Implications for practitioners of sport psychology include using web-based feedback programs such as e-CHUG with their individual clients as part of therapy targeting the reduction of alcohol use as a treatment outcome. 


\section{References}

Abbey, A. (2002). Alcohol-related sexual assault: A common problem among college students. Journal of Studies on Alcohol, Supplement, 14, 118-128.

Baron, R. M., \& Kenny, D. A. (1986). The moderator-mediator variable distinction in social psychological research: Conceptual, strategic, and statistical considerations. Journal of Personality and Social Psychology, 51, 1173-1182.

Bersamin, M., Paschall, M. J., Fearnow-Kenney, M., \& Wyrick, D. (2007). Effectiveness of a web-based alcohol-misuse and harm-prevention course among high- and low-risk students. Journal of American College Health, 55, 247-254.

Borsari, B., \& Carey, K. B. (2003). Descriptive and injunctive norms in college drinking: A meta-analytic integration. Journal of Studies on Alcohol, 64, 331-341.

Borsari, B., \& Muellerleile, P. (2009). Collateral reports in the college setting: A meta-analytic integration. Alcoholism: Clinical and Experimental Research, 33, 826-838.

Carey, K. B., Scott-Sheldon, L. A. J., Carey, M. P., \& DeMartini, K. S. (2007). Individual-level interventions to reduce college student drinking: A meta-analytic review. Addictive Behaviors, 32, 2469-2494.

Chiauzzi, E., Green, T.C., Lord, S., Thum, C., \& Goldstein, M. (2005). My Student Body: A high-risk drinking prevention web site for college students. Journal of American College Health, 53, 263-274.

Collins, R. L., Parks, G. A., \& Marlatt, G. A. (1985). Social determinants of alcohol consumption: The effects of social interaction and model status on the self-administration of alcohol. Journal of Consulting and Clinical Psychology, 53, 189-200.

Cooper, M. L. (2002). Alcohol use and risky sexual behavior among college students and youth: Evaluating the evidence. Journal of Studies on Alcohol Supplement, 14, 101-117.

Dams-O’Connor, K., Martin, J., \& Martens, M. P. (2007). Social norms and alcohol consumption among intercollegiate athletes: The role of athlete and nonathlete reference groups. Addictive Behaviors, 32, 2657-2666.

Doumas, D. M., \& Anderson, L. (2009). Reducing alcohol use in first-year university students: Evaluation of a web-based personalized feedback program. Journal of College Counseling, 18, 18-32.

Doumas, D. M., \& Haustveit, T. (2008). Reducing heavy drinking in intercollegiate athletes: Evaluation of a web-based personalized feedback program. The Sport Psychologist. 22, 212-228.

Doumas, D. M., Kane, C. M., Navarro, T. B., \& Roman, J. (in press). Decreasing heavy drinking in first year students: Evaluation of a web-based personalized feedback program administered during orientation.

Doumas, D. M., McKinley, L., \& Book, P. (2009). Evaluation of two web-based alcohol interventions for mandated college students. Journal of Substance Abuse Treatment, 36, 65-74.

Doumas, D. M., Turrisi, R., Coll, K. M., \& Haralson, K. (2007). High risk drinking in college athletes and nonatheltes across the academic year. Journal of College Counseling, 10, 163-174.

Giacobbi, P. R., Lynn, T .K., Wetherington, J. M., Jenkings, J., Bodendorf, M., \& Langley, B. (2004). Stress and coping during the transition to university for firstyear female athletes. The Sport Psychologist, 18, 1-20.

Grossbard, J., Hummer, J., LaBrie, J., Pederson, E., \& Neighbors, C. (2009). Is substance use a team sport? Attraction to team, perceived norms, and alcohol and marijuana use among male and female intercollegiate athletes. Journal of Applied Sport Psychology, 21, $247-$ 261.

Hildebrand, K., Johnson, D. J., \& Bogle, K. (2001). Comparison of patterns of alcohol use between high school and college athletes and non-athletes. College Student Journal, 35, 358-365.

Hingson, R. W., Heeren, T., Winter, M., \& Wechsler, H. (2005). Magnitude of alcohol-related mortality and morbidity among U.S. college students ages 18-24: Changes from 1998-2001. Annual Review of Public Health, 26, 259-279. 
Hingson, R. W., Heeren, T., Zakocs, R. C., Kopstein, A., \& Wechsler, H. (2002). Magnitude of alcohol-related mortality and morbidity among U.S. college students ages 18-24. Journal of Studies on Alcohol, 63, 136144.

Hummer, J. F., LaBrie, J. W., \& Lac, A. (2009). The prognostic power of normative influences among college student athletes. Addictive Behaviors, 34, 573-580.

Knight, J. R., Wechsler, H., Kuo, M., Seibring, M., Weitzman, E. R., \& Schuckit, M. (2002). Alcohol abuse and dependence among U.S. college students. Journal of Studies on Alcohol, 63, 263-270.

Kypri, K., Saunders, J. B., \& Gallagher, S. J. (2003). Acceptability of various brief intervention approaches for hazardous drinking among university students. Alcohol and Alcoholism, 38, 626-628.

Kypri, K., Saunders, J. B., Williams, S. M., McGee, R. O., Langley, J.D., Cashell-Smith, M. L., et al. (2004). Web-based screening and brief intervention for hazardous drinking: A double-blind randomized controlled trial. Addiction, 99, 1410-1417.

Larimer, M. E., \& Cronce, J. M. (2002). Identification, prevention, and treatment: A review of individual-focused strategies to reduce problematic alcohol consumption by college students. Journal of Studies on Alcohol, Supplement, 14, 148-163.

Larimer, M. E., \& Cronce, J. M. (2007). Identification, prevention, and treatment revisited: Individual-focused college drinking prevention strategies 1999-2006. Addictive Behaviors, 32, 2439-2468.

Leichliter, J., Meilman, P., Presley, C., \& Cashin, J. (1998). Alcohol use and related consequences among students with varying levels of involvement in college athletics. Journal of American College Health, 46, $257-262$.

Lewis, M. A., \& Neighbors, C. (2006). Social norms approaches using descriptive drinking norms education: A review of the research on personalized normative feedback. Journal of American College Health, 54, 213-218.

Martens, M. P., Cimini, D. M., Barr, A. R., Rivero, E. M., Vellis, P. A., Desemone, G.A., et al. (2007). Implementing a screening and brief intervention for high-risk drinking in university-based health and mental health care settings: Reductions in alcohol use and correlates of success. Addictive Behaviors, 32, 2563-2572.

Martens, M. P., Dams-O'Connor, K., \& Beck, N. C., (2006). A systematic review of college student-athlete drinking: Prevalence rates, sport-related factors, and interventions. Journal of Substance Abuse Treatment, 31, 305-316.

Martens, M. P., Dams-O'Connor, K., \& Duffy-Paiement, C. (2006). Comparing off-season with in-season alcohol consumption among intercollegiate athletes. Journal of Sport \& Exercise Psychology, 28, 502-510.

Martens, M. P., Watson, J. C., \& Beck, N. C. (2006). Sport-type difference in alcohol use among intercollegiate athletes. Journal of Applied Sport Psychology, 18, 136-150.

National Collegiate Athletic Association (2001). NCAA study of substance use habits of college student-athletes. Indianapolis, IN: NCAA.

National Institute on Alcohol Abuse and Alcoholism (2003). Task force on recommended questions of the National Council on Alcohol Abuse and Alcoholism: Recommended sets of alcohol consumption questions. Retrieved

October 1, 2009, from http://www.niaaa.nih.gov/Resources/ResearchResources/TaskForce.htm

National Institute on Alcohol Abuse and Alcoholism (2004). National Institute of Alcohol Abuse and Alcoholism Council approves definition of binge drinking. NIAAA Newsletter, 3:3. Retreived October

1, 2009, from http://pubs.niaaa.nih.gov/publications/Newsletter/winter2004/Newsletter_Number3.htm

Neighbors, C., Larimer, M. E., \& Lewis, M. A. (2004). Targeting misperceptions of descriptive drinking norms: Efficacy of a computer-delivered personalized normative feedback intervention. Journal of Consulting and Clinical Psychology, 72, 434-447.

Neighbors, C., Lee, C. M., Lewis, M. A., Fossos, N., \& Larimer, M. E. (2007). Are social norms the best predictor of outcomes among heavy drinking college students? Journal of Studies on Alcohol and Drugs, 68, 556-565.

Nelson, T. F., \& Wechsler, H. (2001). Alcohol and college athletes. Medicine and Science in Sports and Exercise, $15,287-291$.

O’Malley, P. M., \& Johnston, L. D. (2002). Epidemiology of alcohol and other drug use among American college students. Journal of Studies on Alcohol, Suppl., 14, 23-29.

Perkins, H.W. (2002). Social norms and the prevention of alcohol misuse in collegiate contexts. Journal of Studies on Alcohol, 14S, 164-172.

Perkins, H. W., \& Craig, D. W. (2006). A successful social norms campaign to reduce alcohol misuse among college student-athletes. Journal of Studies on Alcohol, 67, 880-888. 
Saunders, J. B., Kypri, K., Walters, S. T., Laforge, R. G., \& Larimer, M. E. (2004). Approaches to brief intervention for hazardous drinking in young people. Alcoholism: Clinical \& Experimental Research, 28, 322-329.

Thombs, D. L. (2000). A test of the perceived norms model to explain drinking patterns among university student athletes. Journal of American College Health, 49, 75-83.

Thombs, D. L., \& Hamilton, M. (2002). Effects of a social norm feedback campaign on the drinking norms and behavior of Division I student-athletes. Journal of Drug Education, 3, 227-244.

Turrisi, R., Mallett, K. A., Mastroleo, N. R., \& Larimer, M. E. (2006). Heavy drinking in college students: Who is at risk and what is being done about it? Journal of General Psychology, 133, 401-421.

Walters, S. T., Miller, E., \& Chiauzzi, E. (2005). Wired for wellness: e-Interventions for addressing college drinking. Journal of Substance Abuse Treatment, 29, 139-145.

Walters, S. T., \& Neighbors, C. (2005). Feedback interventions for college alcohol misuse: What, why, and for whom? Addictive Behaviors, 30, 1168-1182.

Walters, S. T., Vader, A. M., \& Harris, T. R. (2007). A controlled trial of web-based feedback for heavy drinking college students. Prevention Science, 8, 83-88.

Wechsler, H., Davenport, A., Dowdall, G., Moeykens, B., \& Castillo, S. (1994). Health and behavioral consequences of binge drinking in college: A national survey of students at 140 campuses. Journal of the American Medical Association, 272, 1672-1677.

Wechsler, H., Lee, J. E., Kuo, M., \& Lee, H. (2000). College binge drinking in the 1990s: A continuing problem. Results of the Harvard School of Public Health 1999 College Alcohol Study. Journal of American College Health, 48, 199-210.

Wechsler, H., Lee, J. E., Kuo, M., Seibring, M., Toben, N., \& Lee, H. (2002). Trends in college binge drinking during a period of increased prevention efforts. Journal of American College Health, 50, 203-217.

Wechsler, H., \& Nelson, T. F. (2001). Binge drinking and the American college student: What's five drinks? Psychology of Addictive Behaviors, 15, 287-291.

Wechsler, H., \& Nelson, T. F. (2006). Relationship between level of consumption and harms in assessing drink cut-points for alcohol research: on "Many college freshmen drink at levels far beyond the binge threshold" by White et. al. Alcoholism: Clinical and Experimental Research, 30, 922-927.

Vik, P. W., Carrello, P., Tate, S. R., \& Field, C. (2000). Progression of consequences among heavy-drinking college students. Psychology of Addictive Behaviors, 14, 91-101. 


\section{Table 1}

Means and Standard Deviations for Drinking Variables at Baseline and 3 Month Assessments by Study Condition and Drinking Risk-Status

Risk-Status

Condition

Time

High

Low

Total

Weekly Drinking Quantity

$\begin{array}{lllll}\text { Intervention } & \text { Baseline } & 6.50(6.09) & 1.10(2.52) & 2.78(4.67) \\ & 3 \text { Months } & 3.50(4.36) & 2.75(6.34) & 2.98(5.77) \\ \text { Comparison } & \text { Baseline } & 7.08(5.07) & 2.39(4.41) & 3.72(5.02) \\ & 3 \text { Months } & 8.62(9.12) & 3.24(5.40) & 4.76(6.99)\end{array}$

Drinking to Intoxication

$\begin{array}{lllll}\text { Intervention } & \text { Baseline } & 2.22(2.26) & 0.28(0.78) & 0.88(1.67) \\ & 3 \text { Months } & 1.17(1.43) & 0.80(1.80) & 0.91(1.69) \\ \text { Comparison } & \text { Baseline } & 3.15(1.68) & 1.12(1.82) & 1.70(1.99) \\ & 3 \text { Months } & 3.38(2.87) & 0.64(1.32) & 1.41(2.24) \\ \text { Intervention } & \text { Baseline } & 9.22(3.96) & 4.25(5.22) & 5.79(5.36) \\ & \text { 3 Months } & 6.28(4.56) & 3.72(4.85) & 4.52(4.87) \\ \text { Comparison } & \text { Baseline } & 8.92(3.99) & 3.61(4.86) & 5.11(5.19) \\ & & & & \\ & 3 \text { Months } & 9.92(8.91) & 2.97(4.28) & 4.93(6.65)\end{array}$




\section{Table 2}

Means and Standard Deviations for Perception of Peer Drinking at Baseline and 3 Month Assessments by Study Condition and Drinking Risk-Status

Risk-Status

Condition Time High Low Total

Collegiate Athlete Drinking

$\begin{array}{llrrr}\text { Intervention } & \text { Baseline } & 9.56(6.15) & 8.20(6.31) & 8.62(6.24) \\ & 3 \text { Months } & 8.17(6.16) & 9.55(6.91) & 9.12(6.66) \\ \text { Comparison } & \text { Baseline } & 7.85(4.34) & 9.52(7.79) & 9.04(6.99) \\ & \text { 3 Months } & 15.46(12.84) & 11.09(9.04) & 12.33(10.30)\end{array}$

College Student Drinking

$\begin{array}{clccc}\text { Intervention } & \text { Baseline } & 19.83(13.23) & 18.90(14.46) & 19.19(13.98) \\ & \text { 3 Months } & 15.89(8.99) & 19.30(14.19) & 18.24(12.82) \\ \text { Comparison } & \text { Baseline } & 17.23(6.52) & 18.70(11.11) & 18.28(9.97) \\ & \text { 3 Months } & 24.85(16.72) & 18.94(15.23) & 20.61(15.70)\end{array}$




\section{Table 3}

Regression Analyses for Change in Estimates of Peer Drinking as a Mediator on the Effect of the Intervention on Changes in Drinking

Variable

$B$

SE

$\beta$

Step 1

Group x Risk

Step 2

Group x Risk

$\Delta$ Peer Drinking Estimates
3.09

1.51

$.67 *$

Note. $R^{2}=.12, \mathrm{p}<.01$.

$* p<.05, * * p<.02$. 
This is an electronic version of an article published in Journal of Applied Sport Psychology, 22(3). Journal of Applied Sport Psychology is available online at: http://www.informaworld.com/smpp. doi: 10.1080/10413201003666454

\section{Figure Captions}

Figure 1. Changes in Drinking Variables from Baseline to 3 Months

Figure 2. Changes in Perception of Peer Drinking Variables from Baseline to 3 Months 

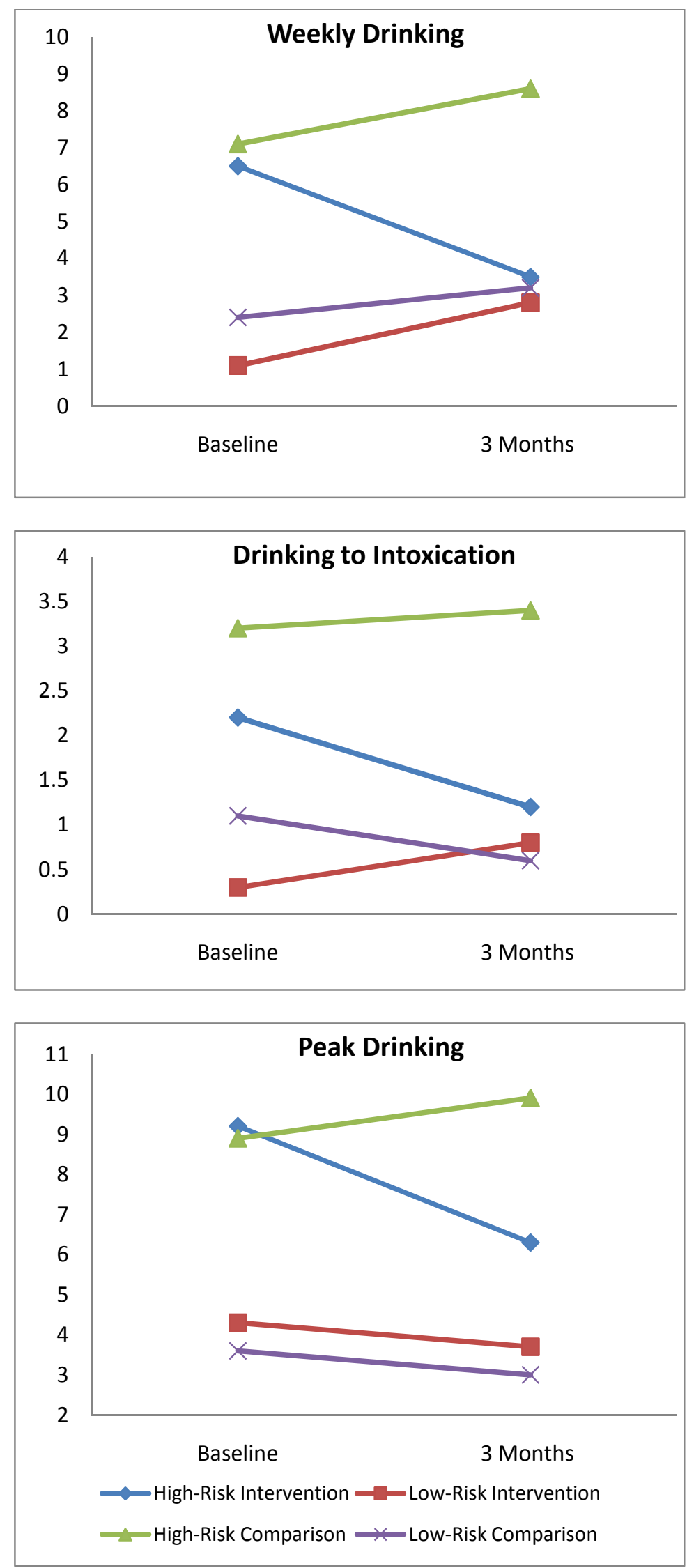

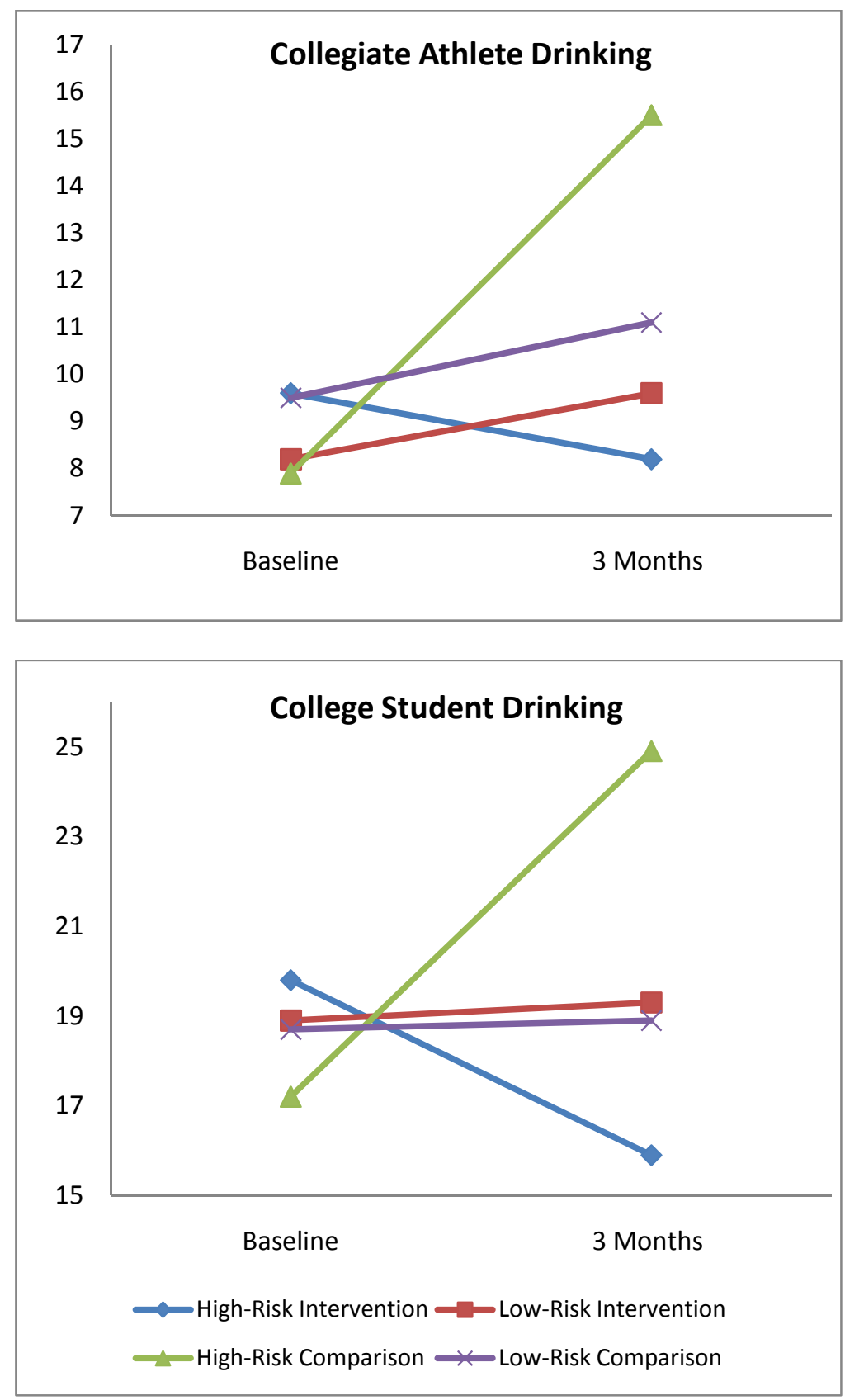